\title{
Towards work-hardenability of Ti-6Al-4V through a quenching and partitioning approach
}

O. Dumas ${ }^{\mathrm{a}, \mathrm{b}}$ (odeline.dumas@chimieparistech.psl.eu), B. Hary ${ }^{\mathrm{a}}$ (benjhary@ulb.ac.be), G. Martin ${ }^{\mathrm{c}}$ (guilhem.martin@simap.grenobleinp.fr), F. Sun ${ }^{\mathrm{b}}$ (fan.sun@ chimieparistech.psl.eu), C. de Formanoir ${ }^{\mathrm{d}}$ (charlotte.deformanoir@kuleuven.be), F. Prima $^{\mathrm{b}}$ (frederic.prima@chimieparistech.psl.eu), S. Godet ${ }^{\mathrm{a}}$ (sgodet@ulb.ac.be)

a4MAT, Université Libre de Bruxelles, Bruxelles, Belgique

${ }^{\mathrm{b}}$ Chimie ParisTech-CNRS, Institut de Recherche de Chimie Paris, Université de recherche PSL, Paris, France

${ }^{\mathrm{c}} \mathrm{SIMaP}, \mathrm{CNRS}$, Grenoble, France

${ }^{d}$ KU Leuven, Dept. of Mechanical Engineering, Celestijnenlaan 300, Heverlee, Belgium

\begin{abstract}
$\underline{\text { Abstract }}$
In this work, the work-hardening ability of Ti-6Al-4V alloy was investigated using a quenching and partitioning strategy on dual-phase Ti-6Al-4V samples. As recently reported [1], it is known that a sub-transus thermal treatment followed by water quenching are able to generate a dual phase $\alpha+\alpha^{\prime}$ microstructure with a remarkable work-hardening coupled with an interesting balance between strength and ductility. Based on this statement, several heat treatments at various subtransus temperatures were performed on as-forged Ti-6Al-4V. In such a way, the respective volume fraction of each phase along with the size and the distance to the equilibrium composition of the quenched martensite are taken as microstructural variables to decompose the work hardenability of dual-phase Ti-6Al-4V alloys into respective contributions. Then, annealing of the metastable $\alpha+\alpha^{\prime}$ microstructure was performed to trigger the $\alpha^{\prime}$ martensite decomposition, involving a partitioning of the alloying elements. The present investigation was carried out on wrought material.
\end{abstract}

The quenching and partitioning parameters led to a wide range of mechanical properties and associated work-hardening behaviour. The as-quenched and further annealed microstructures were characterized by Scanning Electron Microscopy (SEM). The resulting 
mechanical properties were discussed and compared to those of as-forged material.

\section{Introduction}

Ti-6Al-4V is the most widely used titanium alloy covering $50 \%$ of the titanium market and the aerospace industry accounts for more than $80 \%$ of this usage [2]. Designed for high strength at low to moderate temperatures, Ti-6Al-4V displays a high mechanical strength to density ratio and an excellent corrosion resistance. However, the relatively low work hardening of the alloys - which is defined as the difference between the maximum true strength and the yield strength -in comparison to other metals like steels still restricts their usage. Limited work-hardening is associated with low uniform strain (typically in the order of $10 \%$ ) and high sensitivity to strain localization, which is particularly critical for forming [2]. While work-hardening dictates the uniform strain of the material, it has a strong influence on the toughness and tensile strength of metals. Indeed, during ductile fracture, the growth and coalescence of the cavities will be influenced in the first order by the hardening capacity of the material between the growing defects. Improved work-hardening is therefore an important feature for developing materials that exhibit good toughness levels and fatigue resistance and that are defectstolerant. For this purpose, a range of heat treatments based on a quenching and partitioning strategy is considered and proposed as an innovative method to improve the mechanical properties of Ti-6Al-4V parts. The present paper aims at investigating the microstructure, the work-hardening behaviour and the strength/ductility balance resulting from the quenching and partitioning approach for different quenching temperatures and partitioning times.

\section{Material and experiments}

The reference specimen was forged, hot rolled in the $\alpha+\beta$ field, annealed at $730^{\circ} \mathrm{C}$ and finally machined to a $20 \mathrm{~mm}$-diameter section. Its characteristics were in accordance with AMS4928 [3]. Cylindrical tensile specimens were then machined from the industrial bars, encapsulated in quartz tubes under argon atmosphere to prevent from oxygen contamination - and subsequently submitted to heat treatments. The quenching (Q) step consisted in a solution treatment (ST) at sub-transus temperatures, $1123 \mathrm{~K}$ and $1223 \mathrm{~K}$ for $7.2 \mathrm{ks}$ and followed by water quenching (WQ). As shown recently, the ST treatments generate an $\alpha+\alpha$ dual-phase microstructure with a remarkable work-hardening rate coupled with an interesting balance between strength and ductility [1]. The partitioning (P) step 
consisted in an up-quench annealing treatment at $773 \mathrm{~K}$ during $21.6 \mathrm{ks}$. followed by air cooling (AC). Such treatment generates the progressive decomposition of the $\alpha^{\prime}$ martensite. The impact of these post-treatments on the mechanical properties was evaluated by performing tensile tests until fracture on cylindrical specimens at an elongation rate of $1 \mathrm{~mm} / \mathrm{min}$ using Zwick Roell Z100 tensile testing machine. The microstructure was characterized using a FEG LEO 1530 ZEISS scanning electron microscope.

\section{Results and discussion}

\section{Microstructure}

The as-forged specimen is composed of an $\alpha+\beta$ equiaxed microstructure which has been submitted to an annealing treatment at 1003 K. Equiaxed $\alpha$ grains do not exceed $10 \mathrm{~mm}$ while the size of the residual $\beta$ grains are lower or equal to $1 \mathrm{~mm}$. The as-received microstructure, presented in Figure 1.a. comes from the complex industrial processing route [4] and displays a high volume fraction of equiaxed $\alpha$ phase (dark) and a small residual fraction of $\beta$ phase (white zones) inherited from a slow cooling rate after the forging process.

The as-quenched specimens exhibit an $\alpha-\alpha^{\prime}$ dual-phase microstructure (Figure 1.b \& c). Equiaxed $\alpha$ grains coexist with a heterogeneous $\beta$-transformed matrix composed of very thin and acicular laths, characteristic of the self-accommodated quenched martensite, $\alpha^{\prime}$. The amount of $\alpha^{\prime}$ martensite, the number and the size of $\alpha^{\prime}$ martensite laths increase with ST temperature. Therefore, the sample quenched from 1223K (Q 1223K) displays a much larger martensite fraction than the one quenched from 1123K (Q 1123K) ( $81 \%$ compared to $30 \%$ ). However, the large amount of martensite in the Q1223K sample leads to a decrease of the number of $\alpha-\alpha$ ' interphases. The presence of residual $\beta$ was not revealed by the XRD analysis carried out by de Formanoir et al. [1], suggesting that the volume fraction of the remaining $\beta$ should be very low or/and the $\beta$ too fine to be detected.

While heating the initial $\alpha+\beta$ equiaxed microstructure, the $\beta$ proportion gradually increases until it reaches the proportion determined by the phase diagram at the chosen temperatures, namely $1123 \mathrm{~K}$ and $1223 \mathrm{~K}$. Then, fast cooling leads to the martensitic transformation of the stable high-temperature $\beta$ phase into a V-enriched $\alpha^{\prime}$ phase. When the quenching temperature is increased, the $\alpha^{\prime}$ gets more enriched in aluminium and more depleted in vanadium [5]. For this purpose, with the rise of the quenching temperature, the chemical composition of the martensite is closer to the aroom temperature chemical composition and further from that of $\beta$. Consequently, $\alpha$ ' martensite has an out-of-equilibrium composition that changes according to the solution treatment temperatures. Thus, the quenching 
treatment temperature gives rise to $\alpha+\alpha$ dual-phase microstructures with different chemistry for the subsequent martensite decomposition.

After annealing at $773 \mathrm{~K}$ for $21.6 \mathrm{ks}$, the microstructure of the quenched and partitioned samples remains very similar to that of asquenched (Figure 1.d \& e), at the SEM scale of observation. Only some $\beta$ appear to be located in the white areas at the interphases between $\alpha$ and $\alpha^{\prime}$ and in the martensitic areas.
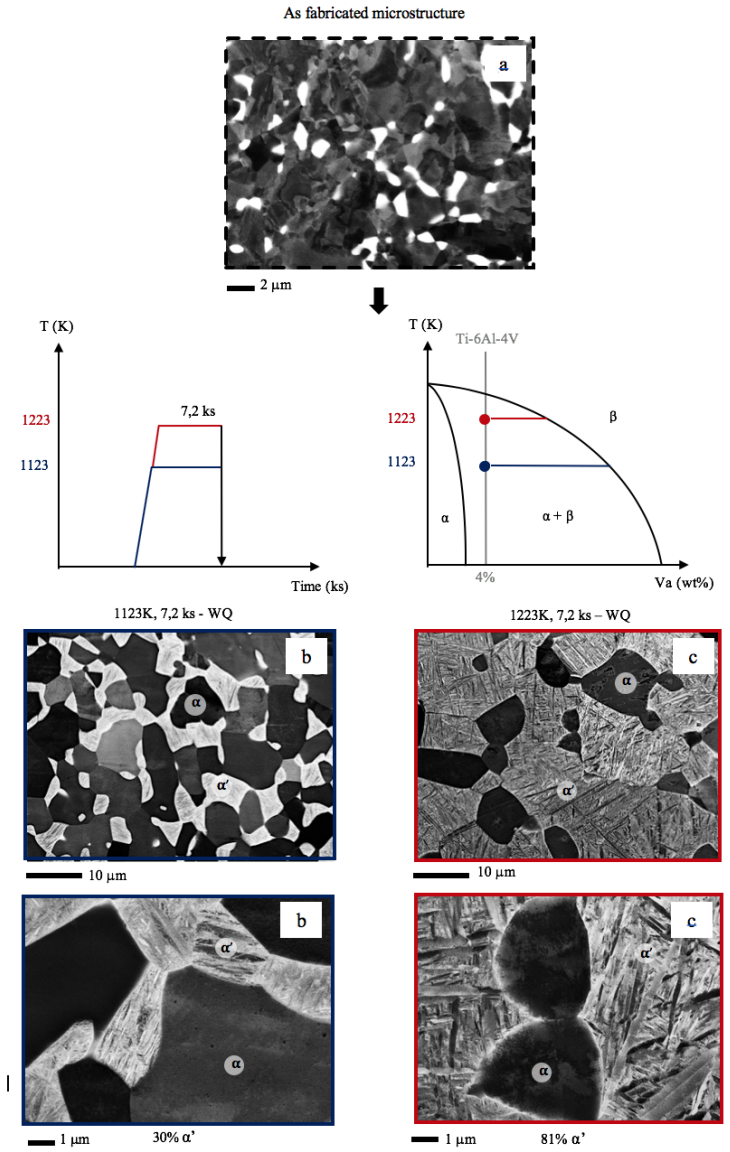

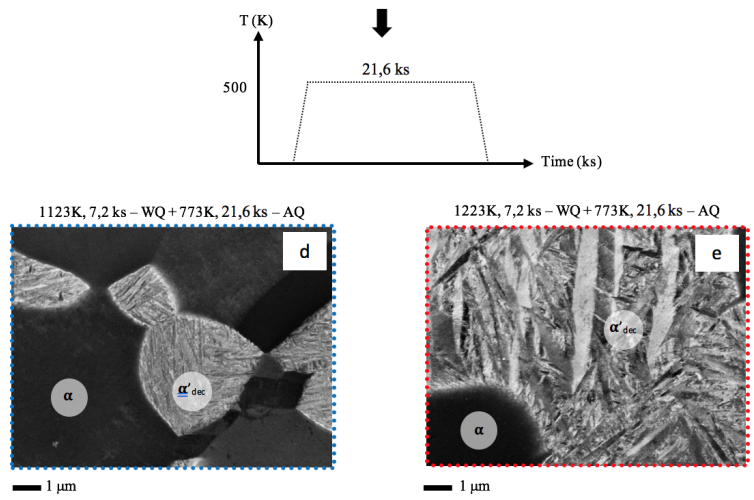

Figure 1. SEM micrographs of as-forged Ti-6Al-4V and heat treated specimens (BSE contrast without etching): (a): as-forged: $\alpha+\beta$ bimodal deformed microstructure with coarsened residual $\beta ;$ (b): 1123K, $7.2 \mathrm{ks,} \mathrm{WQ:} \mathrm{equiaxed} \alpha$ grains and fine laths of $\alpha^{\prime}$ martensite; (c): 1223K, 7.2 ks, WQ; (d): 1123K, $7.2 \mathrm{ks,} \mathrm{WQ} \mathrm{+} \mathrm{773K,} 21.6 \mathrm{ks,} \mathrm{AQ:} \mathrm{equiaxed} \alpha$ grains and fine laths of partially decomposed $\alpha$ ' martensite; (e): 1123K, 21.6 ks, WQ + 773K, $7.2 \mathrm{ks,} \mathrm{AQ}$

Mechanical properties

The tensile properties of as-forged and heat-treated specimens are presented in Figure 2. The as-forged specimen exhibits a typical mechanical behaviour of Ti-6Al-4V $\alpha+\beta$ bimodal microstructure with a relatively high yield strength of 965 MPa, a moderate elongation of $8 \%$ and a very poor work-hardening of $126 \mathrm{MPa}[6]$.

The evolution of the microstructure in as-quenched specimens can be clearly seen (see Q 1123K and Q 1223K in Figure 2). The workhardening is 2 to 3 times higher than in the as-forged conditions. Besides leading to a remarkable increase in work-hardening, the annealing at $1123 \mathrm{~K}$ brings about a high uniform strain $(12 \%$ instead of $8 \%)$ and a promising reduction of area (46\%). However, the yield strength is lowered by $150 \mathrm{MPa}$ and the ultimate tensile strength is comparable to the as-forged specimen. Q $1223 \mathrm{~K}$ also leads to an 
increase of the work-hardening but also to an excellent yield strength of up to $1020 \mathrm{MPa}$, a very high ultimate tensile strength (UTS) of $1164 \mathrm{MPa}$, as well as a high reduction of area $(50 \%)$. On the other hand, it exhibits a low ductility. The work-hardening improvement of such $\alpha+\alpha^{\prime}$ microstructures in Ti-6Al-4V was mainly attributed to a mechanical contrast between the hard $\alpha$ phase and the soft $\alpha$ ' martensitic environment [1]. During loading, deformation gradients are generated in the phases due to a composite load-sharing behaviour between $\alpha$ and $\alpha^{\prime}$ that gives rise to stress concentrations at the interfaces between $\alpha$ and $\alpha^{\prime}$. These deformation gradients are accommodated by the generation of geometrically necessary dislocations promoting work-hardening. The work-hardening is favoured for a microstructure with a martensite proportion close or equal to $50 \%$ that leads to both a high density of $\alpha-\alpha^{\prime}$ interphases and to a good mechanical contrast between a hard $\alpha$ phase and a V-enriched softer $\alpha$ ' martensitic environment. By contrast, at higher martensite proportion, the density of $\alpha-\alpha^{\prime}$ interphases is decreased, and the martensite is enriched in aluminium, which is known to be a strong solution strengthener. As a consequence, the work-hardening and the ductility are lowered while the yield strength is improved. Although their role should be significant, these explanations do not include the contribution of the $\alpha^{\prime}-\alpha^{\prime}$ interphases on the mechanical properties. At this stage, the accurate interpretation of the macroscopic mechanical behaviour is still rather complex for $\alpha+\alpha$ ' microstructures since several contributions such as chemical composition, phase proportions, intrinsic hardness of the phases, $\alpha$ - $\alpha$ ' and $\alpha^{\prime}-\alpha^{\prime}$ interphases density and morphological effects may be involved as numerous possible strengthening mechanisms.

Compared to their respective as-quenched specimens, Q $1123 \mathrm{~K}+\mathrm{P}$ and $1223 \mathrm{~K}+\mathrm{P}$ lead to a significant increase in yield strength up to $1025 \mathrm{MPa}$ and 1105MPa respectively (Figure 2). While the ultimate tensile strength as well as reduction of area are also higher than those in their as-quenched state, the work-hardening is slightly lower. However, the elongations of Q 1123K + P and 1223K + P do not follow the same evolution. The elongation of $\mathrm{P}+\mathrm{Q} 1123 \mathrm{~K}$ sample is lower than the one of Q $1123 \mathrm{~K}$ while the elongation of Q $1223 \mathrm{~K}$ is slightly larger than the one of Q 1223K. Even though as-quenched and quenched + partitioned specimens exhibit a similar microstructure, they display a broad range of mechanical properties. The progressive decomposition of the martensite during the partitioning of the two as-quenched microstructures lead to different mechanical properties. As reported by several authors [5][7][8][9], the decomposition of the martensite leads to a particularly fine $\alpha+\beta$ microstructure. As a result, a bimodal microstructure composed of equiaxed $\alpha$ primary grains and thin secondary $\alpha$ lamellae surrounded by the $\beta$ phase should be promoted by quenching + partitioning treatments. The mechanical behaviour of the Q $1123 \mathrm{~K}+\mathrm{P}$ sample is getting closer to the one of the as-forged. The fine repartition of $\alpha+\beta$ phases should induce a structural hardening effect resulting in a higher yield strength than the as-forged material but a lower work-hardening than its as-quench state, Q 1123K. Indeed, the structural hardening effect of the $\alpha$ ' martensite current decomposition 
decreases the mechanical contrast between $\alpha$ and $\alpha^{\prime}$. The mechanical behaviour of Q 1223K $+\mathrm{P}$ is even more interesting. In that case, an improvement in both the strength and the ductility without significant reduction of the work-hardening is induced by the partioning treatment. In this case, well-balanced mechanical properties between strength, ductility and work-hardening appeared to be caused by higher proportion of the fine distribution of $\alpha$ and $\beta$. A broad range of mechanical properties can be obtained by playing with the $\mathrm{Q}+\mathrm{P}$ heat treatments. The $\mathrm{Q}+\mathrm{P}$ microstructures should be better understood to control the martensite decomposition in order to favour a good compromise between strength and ductility coupled with a good work-hardening. The martensite decomposition mechanisms are

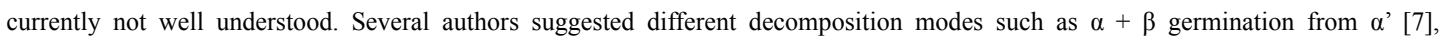
diffusion-controlled martensite decomposition [8] or the formation of intermediate states involving soft martensite $\left(\alpha^{\prime}+\beta_{\mathrm{r}}+\alpha\right.$ à $\alpha^{\prime}$ $+\beta_{\mathrm{r}}+\alpha "+\alpha$ à $\alpha^{\prime}+\beta+\alpha$ à $\left.\alpha+\beta\right)[9]$.
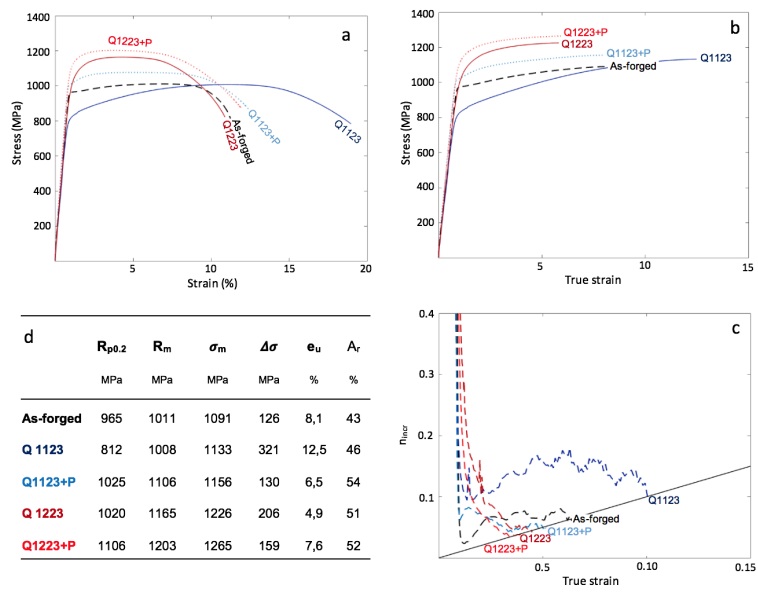

Figure 2. Mechanical properties of as-forged Ti-6Al-4V and heat-treated specimens: (a): Engineering stress-strain curves, (b): True stressstrain curves; (c) : Work-hardening exponent nincr as a function of the strain; (d): Mechanical properties: yield strength Rp0,2, engineering ultimate tensile strength (UTS) Rm, work-hardening : difference between the true UTS and the yield strength

\section{Conclusions}


In this paper, the relationships between microstructures and mechanical properties of Ti-6Al-4V wrought parts submitted to a quenching and partitioning heat treatments strategy were investigated. The heat treatments studied generate a better compromise between the yield strength and the uniform strain coupled with an improved reduction of area for parts made in Ti-6Al-4V. The high work-hardening behaviour observed in $\alpha+\alpha^{\prime}$ dual-phase microstructure results from a work-hardening behaviour rarely obtained for this material thanks to a mechanical contrast between $\alpha$ and $\alpha^{\prime}$. A broad range of tensile properties can be obtained by changing the quenching temperature in order to play on the $\alpha-\alpha^{\prime}$ phase ratio, the chemical composition of the phases and the $\alpha-\alpha^{\prime}$ and $\alpha^{\prime}-\alpha^{\prime}$ interphases density. The partitioning step leads to major changes in the mechanical behaviour of the dual-phase material depending on the variables previously described. The current decomposition of the $\alpha^{\prime}$ martensite into a fine distribution of $\alpha+\beta$ leads to a structural hardening effect resulting in a higher yield strength than the as-forged material but a lower work-hardening than the as-quenched state. Further work should include a fine description of the complex martensitic phase and the contribution of the interphases between $\alpha^{\prime}$ laths.

\section{Aknowledgements}

The authors are grateful to Timet for providing the material and continuous and fruitful discussions.

\section{References}

[1] C. de Formanoir et al., « A strategy to improve the work-hardening behavior of Ti-6Al-4V parts produced by additive manufacturing », Mater. Res. Lett., p. 1-8, oct. 2016.

[2] C. Leyens et M. Peters, Éd., Titanium and Titanium Alloys: Fundamentals and Applications. Weinheim, FRG: Wiley-VCH Verlag GmbH \& Co. KGaA, 2003. «SAE AMS 4928: Titanium Alloy Bars, Wire, Forgings, Rings, and Drawn Shapes 6Al-4V annealed ». SAE International, 07déc-2017.

[4] G. Lütjering, «Influence of processing on microstructure and mechanical properties of alpha+beta titanium alloys », Germany, p. 32-45, 1998. 
[5] C. de Formanoir et al., « Micromechanical behavior and thermal stability of a dual-phase $\alpha+\alpha$ ' titanium alloy produced by additive manufacturing », Acta Mater, vol. 162, p. 149-162, janv. 2019.

[6] G. Lütjering, J.C. Williams, Titanium. Engineering Materials and Processes.

[7] F. X. Gil Mur, D. Rodriguez, et J. A. Planell, « Influence of tempering temperature and time on the a-Ti-6Al-4V martensite », $J$. Alloys Compd., vol. 234, nº 2, p. 287-289, 1996.

[8] S. Cao et al., « Role of martensite decomposition in tensile properties of selective laser melted Ti-6Al-4V », J. Alloys Compd., vol. 744 , p. $357-363$, mai 2018 .

[9] Q. Huang, X. Liu, X. Yang, R. Zhang, Z. Shen, et Q. Feng, « Specific heat treatment of selective laser melted Ti-6Al-4V for biomedical applications », Front. Mater. Sci., vol. 9, nº 4, p. 373-381, 2015. 